\title{
What is new on plant cytogenetics?
}

\author{
Marcelo Guerra \\ Universidade Federal de Pernambuco, Departamento de Botânica, Laboratório de Citogenética Vegetal, \\ Recife, PE, Brazil.
}

\section{Plant Cytogenetics. Naranjo T and Puertas MJ (eds) (2005). Karger Medical and Scientific Publishers, Basel. 408 pp. Hardcover 172 USD. ISBN 3-8055-7899-7.}

Received: May 16, 2005; Accepted: May 25, 2005.

Plant chromosomes have traditionally been a fruitful material for almost every kind of cytogenetic research. However, in the last two decades, with the development of cytomolecular techniques, mainly FISH (Fluorescent In Situ Hybridization) and its numerous variants, plant cytogenetics research has greatly advanced, revealing unexpected details of chromosome behavior and evolution.

The book, Plant Cytogenetics, edited by the Spanish cytogeneticists Maria Puertas and Tomás Naranjo and carefully published by Karger as a reprint of Cytogenetic and Genome Research, v. 109, number 1-3, offers us a wide variety of themes on this subject. The hardbound volume consists of 51 peer-reviewed articles on 408 glossy pages, 182 figures (81 in colour) and 54 tables. As a single topic issue it constitutes a well-done review of the current research on plant cytogenetics. Two important themes were apparently intentionally not emphasized: B chromosomes and DNA content, both recently thoroughly reviewed (the former in another special volume of this same journal and the latter in a special issue of Biological Journal of the Linnean Society, August/2004, and in Annals of Botany, January/2005).

The book is divided in five sections (Cytogenetics and Genomics, Physical Mapping; Nuclear and Chromosome Organization; Cell Division, Mitosis and Meiosis; Chromosome Evolution and Plant Breeding, and Cytogenetics and Plant Breeding), but this division is not always so clear. Although general cytogenetics is well treated, the cytogenetics of cultivated grasses is the subject of most of the articles, with about 20 of them dealing specifically with the tribe Triticeae (wheat, rye, barley, etc) and several others dealing with maize, oat, sugarcane, the Lolium-Festuca complex, rice, etc.

Send correspondence to Marcelo Guerra. Universidade Federal de Pernambuco, Departamento de Botânica, Laboratório de Citogenética Vegetal, Rua Prof. Nelson Chaves, s/n, 50.670-420 Recife, PE, Brazil. E-mail: msfguerra@hotmail.com.
Indeed, the cytogenetics of grasses has always been the most advanced area in plant cytogenetics and when combined with FISH and GISH (Genomic In Situ Hybridization) it furnishes a flexible model to study the behavior of individual genomes, individual chromosomes, or chromosomal fragments in natural and artificial hybrids. Since most plants, notoriously the cultivated ones, originated from one or two hybridization events followed by polyploidization, this technique has become the most common way to analyze allopolyploids, and again grasses. Furthermore, the many chapters discuss very well the gene and chromatin introgression of wild species into cultivated ones not only concerning Triticeae but also other genera, such as Solanum and Beta. In several aspects, the cytogenetics of hybrids has also received special attention in this volume, mainly concerning plant breeding. Since hybrid derivatives may contain a variable number of alien chromosomes or chromosome arms, the use of GISH opens the doors to a clear genome distinction where before there was a lot of speculations. It also offers the possibility of analysing "painted chromosomes" through the whole cell cycle, elegantly demonstrated in colourful photographs.

Another important topic in this volume is meiosis. In spite of being by far the shortest section, it touches on some important questions regarding plant meiosis (the meiotic proteome, homologous recognition and reciprocal exchange, recombination nodules, the meiosis of haploids and polyploids, and the genetic control of meiosis). Many other current issues, like chromosome microdissection, distribution and organization of retrotransposons, 3D chromosome architecture, strand-specific FISH, the telomeres of plants lacking the classical Arabidopsis telomere sequence, kinetochores and neocentromeres, histone phosphorylation, molecular analysis of holocentric chromosomes, the debated genetic diploidization of polyploids, the plant meiotic proteome, physical mapping on pachytene chromosomes and on extended DNA fibers, the changes in nuclear domains during microspore embryogenesis, the chromosomal distribution of different kinds of repetitive sequences, and several other advanced approaches to plant cytogenetics are discussed in separated papers. As a bonus, McClintock's elements are delightfully reviewed. 
Besides such venerable protagonists of the plant cytogenetics stage, some beginning actors, like citrus and banana chromosomes, take their place in this volume, and the almost unknown Torenia fournieri appears as a model plant for karyological analyses in interspecific fertilization and early embryogenesis. On the other hand, the prima dona, Arabidopsis thaliana, found no place here, among such (chromosomal) giants.

As nothing is perfect, there is also a very few unexpressive papers, including an unnewsworthy review of dinoflagellate chromosomes, and the reader will miss a subject index - but these detractions do little to blemish this extraordinary selection of papers on plant cytogenetics.

Editor: Fábio de Melo Sene 